\title{
Void Fraction in a Four by Four Rod Bundle under a Stagnant Condition*
}

\author{
Akihiro KAMEI**, Shigeo HOSOKAWA**, Akio TOMIYAMA*, \\ Ikuo KINOSHITA*** and Michio MURASE*** \\ ** Graduate School of Engineering, Kobe University \\ 1-1 Rokkodai, Nad, Kobe, Hyogo 657-8501, Japan \\ E-mail: tomiyama@mech.kobe-u.ac.jp \\ ${ }^{* * *}$ Institute of Nuclear Safety System, Inc. \\ 64 Sata, Mihama-cho, Mikata-gun, Fukui 919-1205, Japan
}

\begin{abstract}
In the case of a hypothetical failure of a residual heat removal (RHR) systems under mid-loop operation, vapor generated in a reactor core forms two-phase flow in a stagnant liquid and rises the water level in the core. The vapor flows into a steam generator through a hot leg, and condenses in the steam generator. Since the flow rate of vapor from the reactor core to the hot leg depends on the water level and the void fraction $\alpha$ in the reactor core, the reliable analysis of the RHR failure cannot be carried out without accurately estimating the void fraction in the reactor core. Although a number of studies on void fractions in two-phase flows in rod bundles have been carried out, there are few experimental data on void fractions in rod bundles under the stagnant condition. Void fractions in four by four rod bundles under the stagnant condition were measured for a wide range of gas volume fluxes to examine the validity of available void correlations. Flow patterns were visualized by using a high-speed video camera to examine the effects of flow pattern on the void fraction. As a result, the following conclusions were obtained: (1) Dependence of the void fraction on the gas volume flux $J_{G}$ changed at $J_{G} \cong 1.5 \mathrm{~m} / \mathrm{s}$ due to the flow pattern transition. (2) Murase's correlation agreed well with the void fraction in the two kinds of rod bundles having different dimensions under the stagnant condition.
\end{abstract}

Key words : Gas-Liquid Two-Phase Flow, Nuclear Reactor, PWR, Void Fraction, Rod Bundle, Stagnant Condition

\section{Introduction}

During a PWR plant outage for maintenance or refueling, the level of the primary coolant must be kept at the center of a hot leg and the reactor coolant is cooled by residual heat removal (RHR) systems. This operation is called "mid-loop operation". If a hypothetical failure of the RHR system occurs during the mid-loop operation, there is a possibility of water boiling and core exposure. In this case, the vapor generated in the reactor core forms two-phase flow in a stagnant liquid and rises the water level in the reactor core. The vapor flows into a steam generator through the hot leg, and condenses in the steam generator. Since the condensed water flows back to the reactor core, counter-current two-phase flow is formed in the hot leg. This process is the so-called reflux cooling. Minami et al. ${ }^{(1)}$ carried out experiments on counter-current gas-liquid two-phase flows in a hot-leg, and they pointed out that characteristics of counter-current flow depend on the water level and void fraction in the reactor core. Hence, an accurate estimation of the void fraction in the core is required to improve the reliability of the RHR failure analysis ${ }^{(2),(3)}$. Although a number of studies on void fractions in two-phase flows in rod bundles have been carried out ${ }^{(4),(5)}$, there are few experimental data on void fractions in rod bundles under a stagnant condition ${ }^{(6),(7)}$.

${ }^{*}$ Received 30 Apr., 2010 (No. 10-0187) [DOI: 10.1299/jpes.4.315]

Copyright $\subset 2010$ by JSME 
There are several correlations for void fraction in stagnant liquid. Kataoka and Ishii (8) proposed a void correlation for two-phase flow in a pool based on the drift flux model. However, its applicability to rod bundle geometry has not been tested yet due to the lack of experimental data. Murase et al. ${ }^{(9)}$ proposed a void correlation, which is applicable not only to pipe flows but also to flows in a rod bundle geometry. They confirmed its applicability to low gas volume flux conditions only.

In this study, void fractions in four by four rod bundles under the stagnant condition are measured for a wide range of gas volume fluxes to examine the validity of the available void correlations. Flow patterns are visualized by using a high-speed video camera to examine the effects of flow pattern on the void fraction.

Nomenclature

\begin{tabular}{|c|c|c|}
\hline$C_{0}$ & : distribution parameter & \\
\hline$D_{W}$ & : hydraulic diameter & {$[\mathrm{m}]$} \\
\hline$D^{*}$ & : dimensionless hydraulic diameter & \\
\hline$g$ & : acceleration of gravity & {$\left[\mathrm{m} / \mathrm{s}^{2}\right]$} \\
\hline$J$ & volume flux & {$[\mathrm{m} / \mathrm{s}]$} \\
\hline$J^{*}$ & dimensionless volume flux & \\
\hline$T$ & : time & {$[\mathrm{s}]$} \\
\hline$V$ & : velocity & {$[\mathrm{m} / \mathrm{s}]$} \\
\hline$V_{G J}$ & drift velocity & {$[\mathrm{m} / \mathrm{s}]$} \\
\hline$\alpha$ & volume fraction & \\
\hline$\Delta P$ & pressure drop & {$[\mathrm{Pa}]$} \\
\hline$\rho$ & : density & {$\left[\mathrm{kg} / \mathrm{m}^{3}\right]$} \\
\hline$\sigma$ & $: \quad$ surface tension & {$[\mathrm{N} / \mathrm{m}]$} \\
\hline
\end{tabular}

Subscripts

$G \quad$ : gas phase

$L \quad$ : liquid phase

\section{Experimental Apparatus and Method}

Figures1 and 2 show schematics of the experimental apparatus and the cross-section of the test section. The experimental apparatus consists of the test section, the upper tank and the lower tank. The test section consists of the channel box and sixteen rods positioned by the upper and lower tieplates (see Figs. A and B in Appendix). The channel box was made of acrylic resin to observe flow patterns in the rod bundle. The rod diameter and the rod pitch were 10 and $12.3 \mathrm{~mm}$, respectively. These values were determined by referring to the geometry of a typical PWR fuel assembly. The hydraulic diameter $D_{W}$ of the test section was $9.0 \mathrm{~mm}$. Air and tap water at atmospheric pressure and room temperature were used for the gas and liquid phases, respectively. Air was supplied from the compressor (Hitach, Oil free compressor, SRL-11) and injected into stagnant water through the diffuser plate in the lower tank. The diffuser plate was made of a porous media (thickness: $4 \mathrm{~mm}$ ) and bubbles were injected from the plate. The gas volume flux $J_{G}$ was varied from 0.03 to $8.0 \mathrm{~m} / \mathrm{s}$ to cover a wide range of void fractions $\alpha$. The uncertainty in measured $J_{G}$ estimated at $95 \%$ confidence was less than $7.0 \%$.

Instantaneous pressure drops, $\Delta P(t)$, in the section $L_{3}$ in Fig. 1 were measured by using differential pressure transducers (Nidec Copal Electronics Co., PA-100 500D-W). Here, $t$ is the time. The signals from the pressure transducers were recorded by using a digital recorder (Yokogawa, WE-7000). The pressure drops were measured simultaneously at the four sides of the channel box. The sampling frequency was $200 \mathrm{~Hz}$. The time-averaged pressure drops 
$\Delta P$ was calculated by

$$
\Delta P=\frac{1}{T} \int_{0}^{T} \Delta P(t) d t
$$

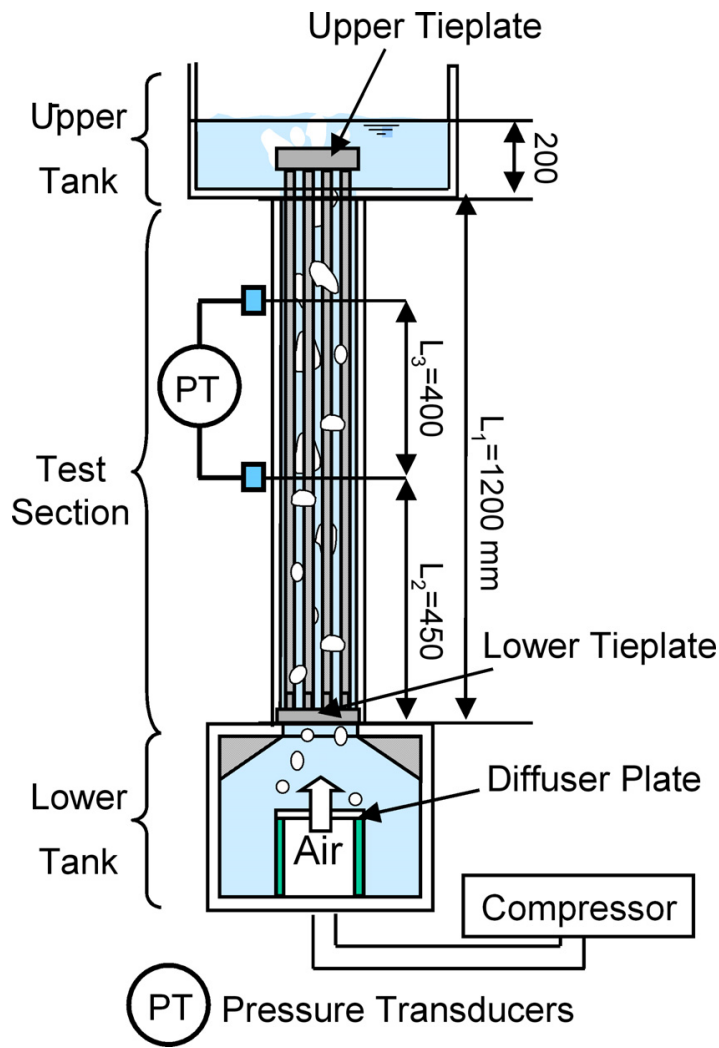

Fig. 1 Experimental apparatus

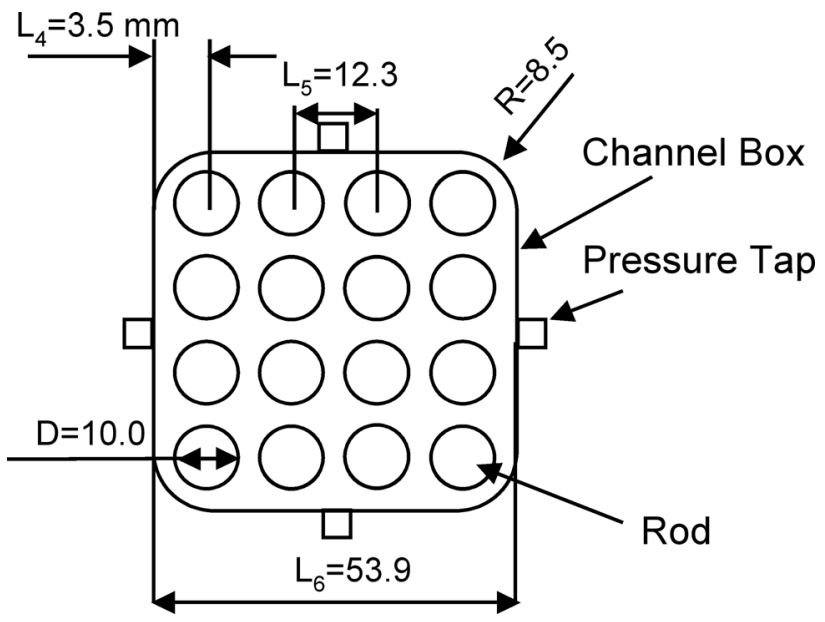

Fig. 2 Cross section of the rod bundle

where $T$ is the time scale for averaging. Figure 3 shows a relationship between $T$ and $\Delta P$. Since $\Delta P$ became constant for $T>100$ seconds, pressure drops were measured for more than 250 seconds to obtain accurate time-averaged pressure drops $\Delta P$. 
The void fraction $\alpha$ and the phase-averaged gas velocity $V_{G}$ were evaluated from the pressure drops $\Delta P$ by using the following equations:

$$
\begin{aligned}
& \alpha=1-\frac{\Delta P}{\left(\rho_{L}-\rho_{G}\right) g L} \\
& V_{G}=\frac{J_{G}}{\alpha}
\end{aligned}
$$

where $\rho$ is the density, $g$ the acceleration of gravity, $L$ the length of the section $L_{3}$ and the subscripts $G$ and $L$ denote the gas and liquid phases, respectively.

Flow in the test section was visualized by using a high-speed camera (Redlake, MotionPro HS-1). The flow pattern was judged from the recorded movies.

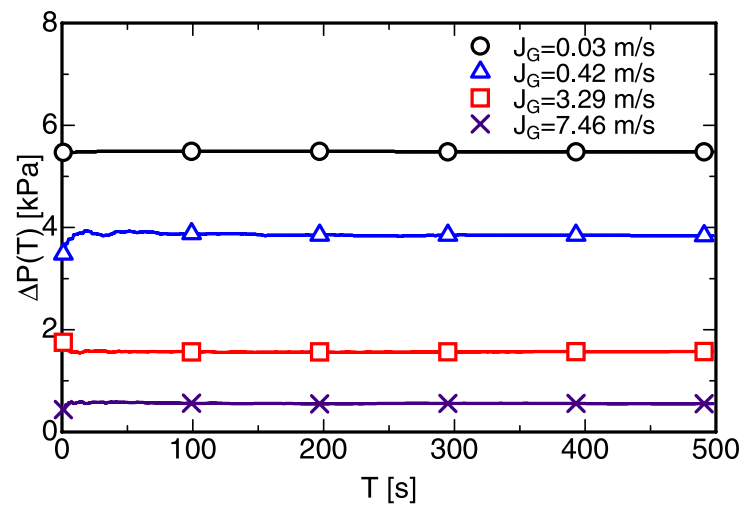

Fig. 3 Effect of the time scale $T$ on the time-averaged pressure drop $\Delta P$

\section{Result and Discussion}

\subsection{Flow pattern}

Figure 4 shows flow patterns in the rod bundle. Flow patterns were classified into six regimes shown in Table1 based on the authors' previous study ${ }^{(10)}$. The flow is bubbly at low $J_{G}$ as shown in Fig. 4(a). As $J_{G}$ increases, large bubbles are generated as shown in Fig. 4(b) (regime of transition from bubbly to churn A). As $J_{G}$ further increases, the flow pattern changes to churn flow (Fig. 4(c), (d), (e)). In the churn flow, two kinds of flow patterns appear. As shown in Fig. 4(c), when the gas flow rate is not so large, there are no large bubbles covering most of the cross section. At high $J_{G}$, large bubbles covering most of the cross section sometimes appear as shown in Fig. 4(e). We call the former flow pattern (Fig. 4(c)) "churn A" and the latter flow pattern (Fig. 4(e)) "churn B". Though the former could be called either "slug flow" or "churn flow", we refer it as to "churn A" because Taylor bubbles, which characterize slug flow, were not present. Further increase in $J_{G}$ induces the transition to annular flow (Fig. 4 (f)).

Flow patterns are summarized in Fig. 5. The transition from bubbly to churn occurs at $J_{G} \cong 0.1 \mathrm{~m} / \mathrm{s}$, the transition from churn A to churn B takes place at $J_{G} \cong 1.5 \mathrm{~m} / \mathrm{s}$, and the transition from churn to churn to annular occurs at $J_{G} \cong 6.0 \mathrm{~m} / \mathrm{s}$.

\subsection{Void fraction}

Figure 6 shows measured mean pressure drops at the four sides. There is no difference in $\Delta P$ among the four sides. The void fraction $\alpha$ and phase-averaged gas velocity $V_{G}$ were, therefore, calculated by using the arithmetic mean of the four pressure drops.

Figures 7 (a) and (b) show $\alpha$ and $V_{G}$, respectively. The void fraction $\alpha$ increases with $J_{G}$. Although the gradient of $\alpha$ decreases with increasing $J_{G}$ for $J_{G}<1.5 \mathrm{~m} / \mathrm{s}$, it increases at 
Table 1 Definition of flow patterns

\begin{tabular}{l|l}
\hline Flow pattern & Definition \\
\hline Bubbly & $\begin{array}{l}\text { Flow with small bubbles } \\
\text { Bubbly to churn A }\end{array}$ \\
$\begin{array}{l}\text { Formation of large bubbles whose vertical lengths are longer than } \\
2 D_{W} \\
\text { Highly agitated intermittent flow with many large distorted bubbles } \\
\text { which induce downward flows in their circumferences }\end{array}$ \\
$\begin{array}{l}\text { Transition from churn A to churn B } \\
\text { Churn A to churn B }\end{array}$ & $\begin{array}{l}\text { Highly agitated flow with huge gas lumps covering most of the } \\
\text { cross-section } \\
\text { Annular flow in the center region of the bundle and churn flow in the } \\
\text { peripheral region }\end{array}$ \\
\hline
\end{tabular}

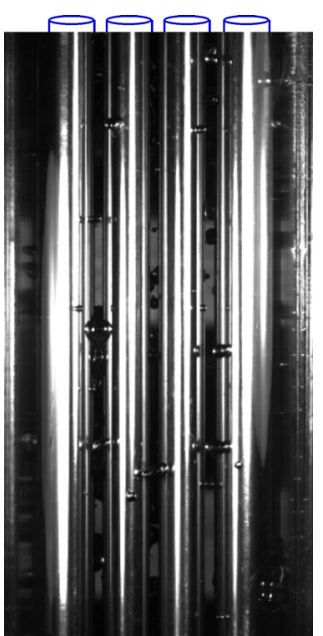

(a) Bubbly

$\left(J_{G}=0.03 \mathrm{~m} / \mathrm{s}\right)$

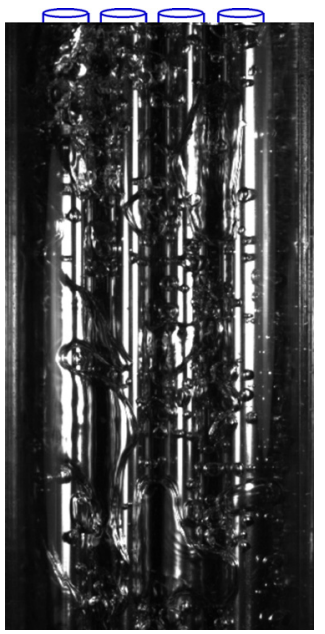

(d) Churn A to churn B $\left(J_{G}=1.34 \mathrm{~m} / \mathrm{s}\right)$

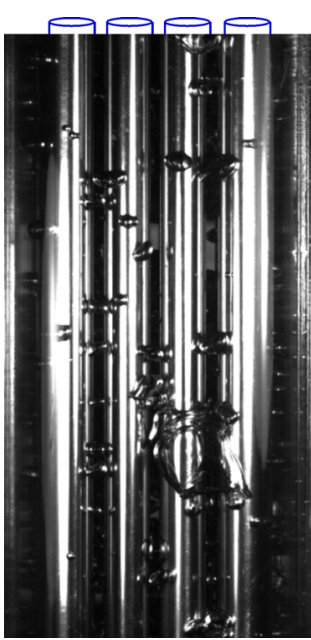

(b) Bubbly to churn A $\left(J_{G}=0.06 \mathrm{~m} / \mathrm{s}\right)$

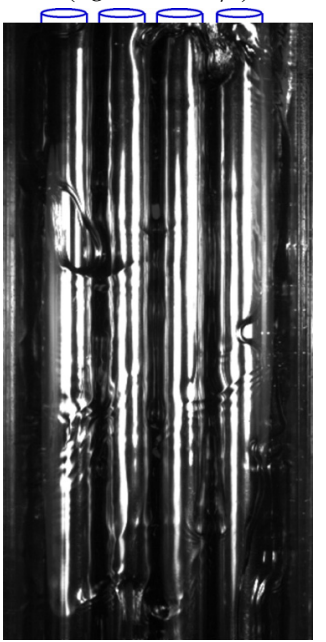

(e) Churn B

$\left(J_{G}=2.85 \mathrm{~m} / \mathrm{s}\right)$

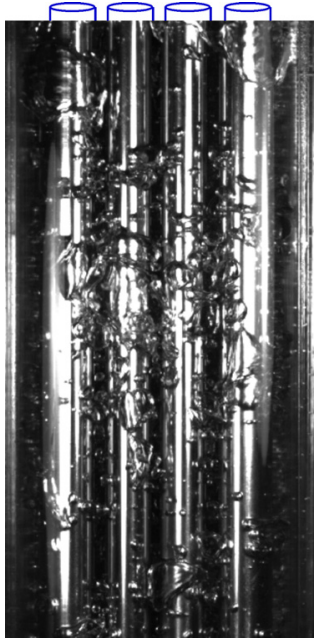

(c) Churn A

$\left(J_{G}=0.42 \mathrm{~m} / \mathrm{s}\right)$

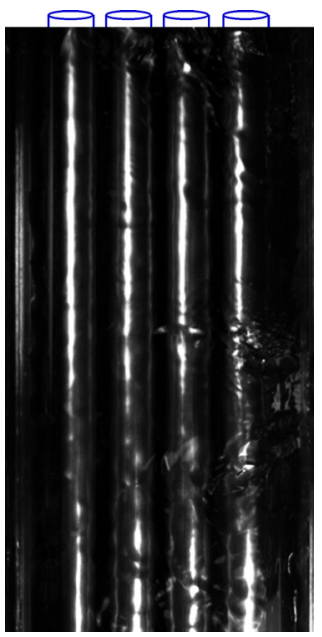

(f) Churn B to annular $\left(J_{G}=8.85 \mathrm{~m} / \mathrm{s}\right)$

Fig. 4 Flow patterns

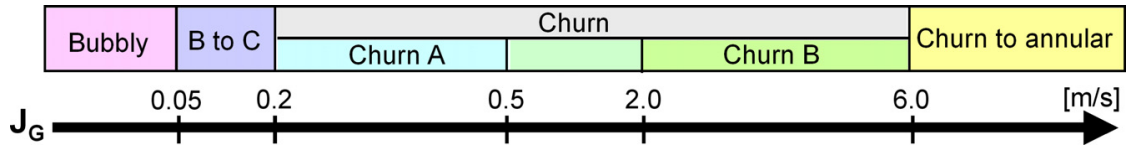

Fig. 5 Flow pattern map 
$J_{G} \cong 1.5 \mathrm{~m} / \mathrm{s}$ and decreases again with increasing $J_{G}$. The phase-averaged gas velocity $V_{G}$ increases with $J_{G}$, and its gradient also changes at $J_{G} \cong 1.5 \mathrm{~m} / \mathrm{s}$. By dividing the data into two groups at $J_{G}=1.5 \mathrm{~m} / \mathrm{s}, \alpha$ and $V_{G}$ are well correlated by using the drift-flux model ${ }^{(11)}$ :

$$
\begin{gathered}
\alpha=\frac{J_{G}}{C_{o} J_{G}+V_{G J}} \\
V_{G}=C_{o} J_{G}+V_{G J}
\end{gathered}
$$

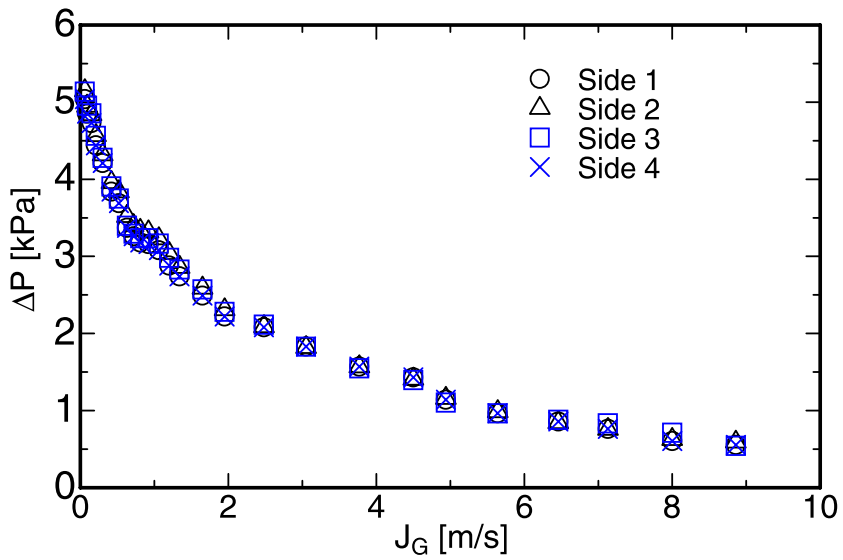

Fig. 6 Differential pressures on four sides

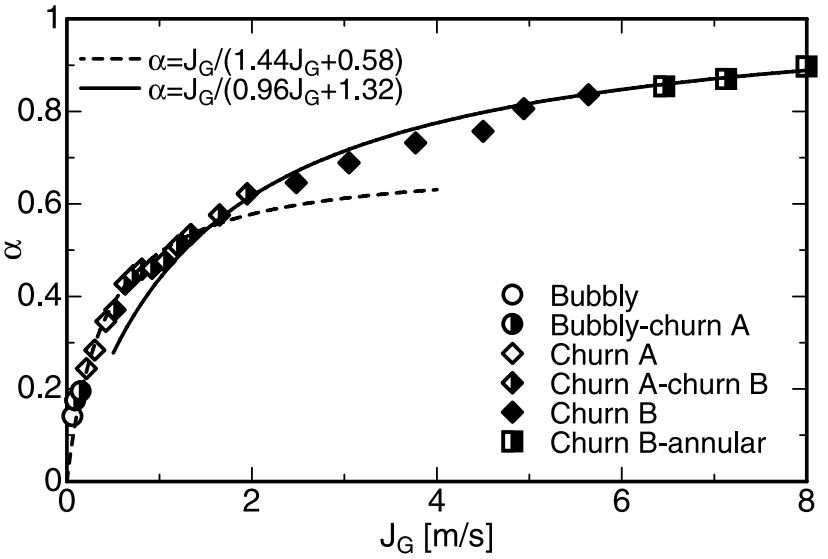

(a) Void fraction

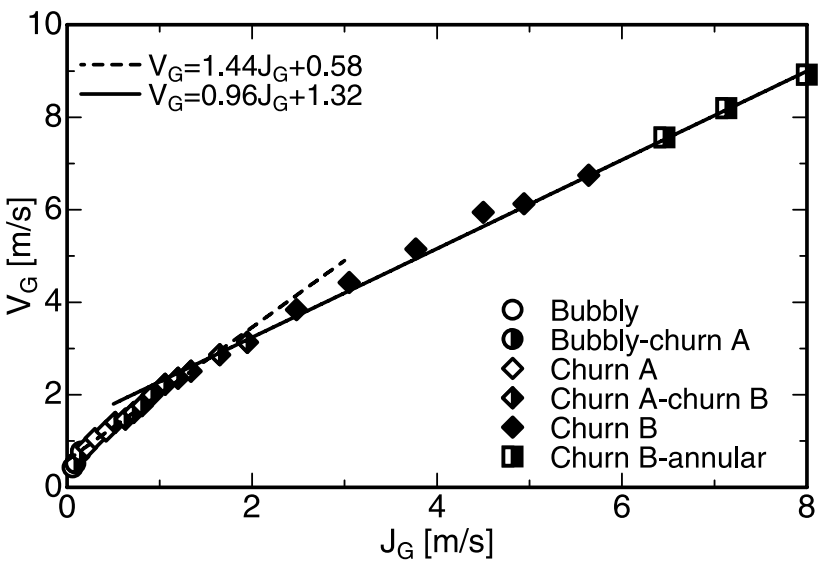

(b) Gas velocity

Fig. 7 Void fraction and gas velocity 
where $C_{0}$ is the distribution parameter and $V_{G J}$ the drift velocity. The values of $C_{0}$ and $V_{G J}$ in the regression lines in Fig. 7(b) are 1.44 and $0.58 \mathrm{~m} / \mathrm{s}$ for $J_{G}<1.5 \mathrm{~m} / \mathrm{s}$, and 0.96 and 1.32 $\mathrm{m} / \mathrm{s}$ for $J_{G} \geq 1.5 \mathrm{~m} / \mathrm{s}$. The gradient $C_{0}$ for $J_{G} \geq 1.5 \mathrm{~m} / \mathrm{s}$ is smaller than that for $J_{G}<1.5 \mathrm{~m} / \mathrm{s}$. The correlation coefficients between the lines and data are 0.988 and 0.998 for $J_{G}<1.5 \mathrm{~m} / \mathrm{s}$ and $J_{G} \geq 1.5 \mathrm{~m} / \mathrm{s}$, respectively. This decrease is due to the flow pattern transition, that is, the formation of large bubbles, which block the cross-section. Note that the values of $C_{0}$ and $V_{G J}$ for $J_{G} \geq 1.5 \mathrm{~m} / \mathrm{s}$ are close to those for annular pipe flow $\left(C_{0} \cong 1.0, V_{G J}=0.7 \sim 1.7 \mathrm{~m} / \mathrm{s}\right)^{(12)}$.

Kataoka and Ishii ${ }^{(8)}$ proposed correlations of $C_{0}$ and $V_{G J}$ for gas-liquid two-phase flow in a pool:

$$
\begin{aligned}
& C_{0}=1.2-0.2 \sqrt{\frac{\rho_{G}}{\rho_{L}}} \\
& V_{G J}=V_{G J}^{+}\left(\frac{\sigma g\left(\rho_{L}-\rho_{G}\right)}{\rho_{L}^{2}}\right)^{\frac{1}{4}}
\end{aligned}
$$

where $\sigma$ is the surface tension and $V_{G J}^{+}$is given by

$$
V_{G J}^{+}=0.009 D^{* 0.809}\left(\frac{\rho_{G}}{\rho_{L}}\right)^{-0.157} N_{\mu}^{-0.562}
$$

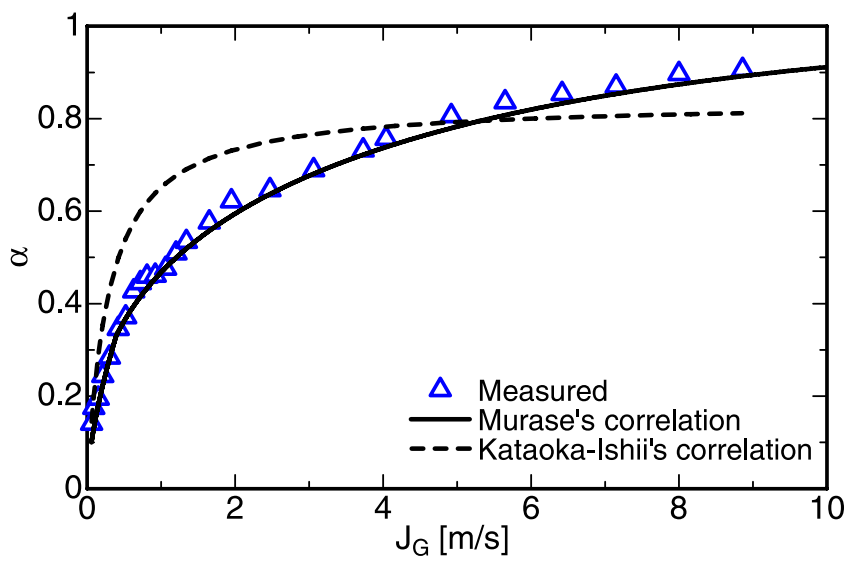

(a) Void fraction

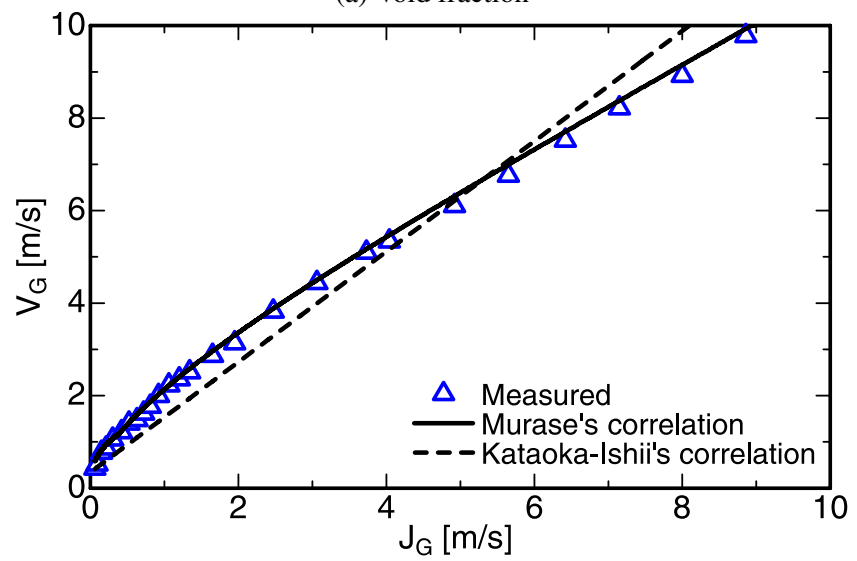

(b) Gas velocity

Fig. 8 Comparison among measured data, Kataoka-Ishii's correlation and Murase's correlation 


$$
N_{\mu}=\frac{\mu}{\left(\rho_{L} \sigma \sqrt{\frac{\sigma}{g\left(\rho_{L}-\rho_{G}\right)}}\right)^{\frac{1}{2}}}
$$

where $\mu$ is the viscosity and $D^{*}$ is the dimensionless hydraulic diameter defined by

$$
D^{*}=D_{W} \sqrt{\frac{g\left(\rho_{L}-\rho_{G}\right)}{\sigma}}
$$

Murase et al. ${ }^{(9)}$ proposed a void correlation for gas-liquid two-phase flows in rod bundles:

$$
\begin{aligned}
& \alpha=0.037 Y^{1.68} \quad \alpha \leq 0.33 \\
& 1-\alpha^{1.45}=\exp (-0.061 Y) \quad 0.33<\alpha
\end{aligned}
$$

where

$$
Y=\frac{1}{1.7 D^{* 0.125}} \frac{J_{G}^{*}}{\alpha}
$$

where $J_{G} *$ is the dimensionless gas volume flux defined by

$$
J_{G}^{*}=J_{G}\left[\frac{\rho_{L}^{2}}{g \sigma\left(\rho_{L}-\rho_{G}\right)}\right]^{\frac{1}{4}}
$$

Figure 8 shows comparisons between the above correlations and the measured data. The phase-averaged gas velocity $V_{G}$ in Fig. 8 (b) was calculated as $V_{G}=J_{G} / \alpha$. Kataoka and Ishii's correlation does not agree with the measured data. This might be because it was developed for two-phase flow in a pool, which does not include fuel rods. On the other hand, Murase's correlation gives a good prediction for the whole range of void fraction.

\subsection{Other bundle geometry}

Void fractions in the rod bundle shown Fig. 1 were well predicted by using Murase's correlation. Then, pressure drops in another bundle was measured to examine whether or not Murase's correlations is applicable to another bundle having different dimensions. The sizes of the two bundles tested are summarized in Table 2. Hereafter, the two bundles are called "bundle A" $\left(D_{W}=9.0 \mathrm{~mm}\right)$ and "bundle B" $\left(D_{W}=12.7 \mathrm{~mm}\right)$, respectively. The former is the bundle shown in Figs. 1 and 2. The geometry of the latter bundle was determined by referring to the geometry of a typical BWR fuel assembly. As shown in Fig. 9, Murase's correlation agrees well with the measured data not only for the bundle A (see Fig. 8) but also for the bundle B.

Table 2 The dimensions of the test sections (unit $\mathrm{mm}$ )

\begin{tabular}{c|ccccccccc}
\hline Bundle & $L_{1}$ & $L_{2}$ & $L_{3}$ & $L_{4}$ & $L_{5}$ & $L_{6}$ & $D$ & $R$ & $D_{W}$ \\
\hline A & 1200 & 450 & 400 & 3.5 & 12.3 & 53.9 & 10.0 & 8.5 & 9.0 \\
B & 1400 & 760 & 400 & 4.0 & 16.0 & 68.0 & 12.0 & 10.0 & 12.7 \\
\hline
\end{tabular}




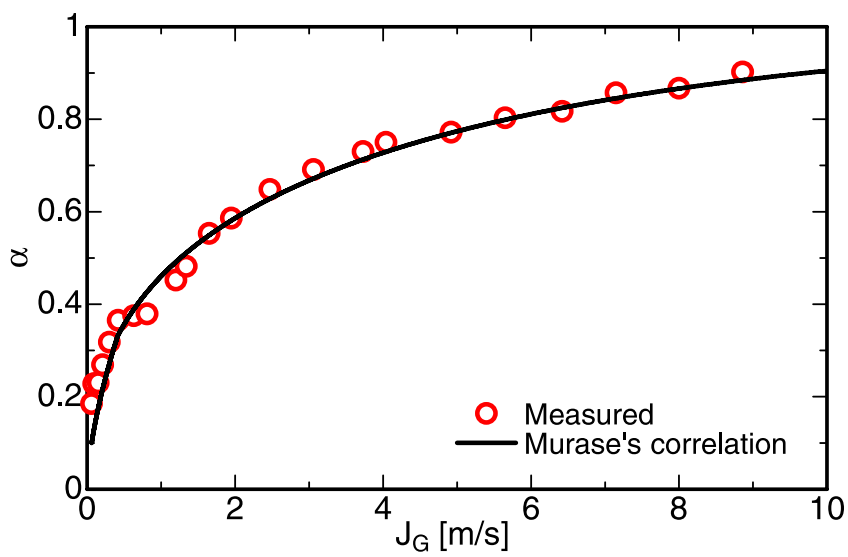

(a) Void fraction

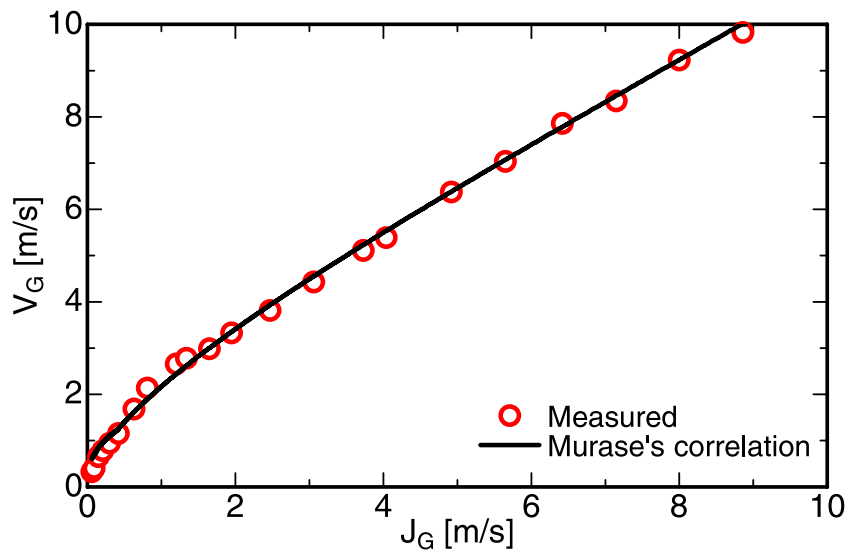

(b) Gas velocity

Fig. 9 Comparison between measured data in bundle B and Murase's correlation

Murse's correlation consists of two equations; Eq. (11) for $\alpha \leq 0.33$ and Eq. (12) $\alpha>$ 0.33. As shown in Fig. 10, the difference between the void fractions evaluated by Eqs. (11) and (12) is negligible for $\alpha \leq 0.33$. That is, the void fraction can be accurately evaluated by using Eq. (12) only for the whole range of $\alpha$. Note that $\alpha$ does not change so much between the bundles A and B, whereas $D_{W}$ of the bundle B is by $40 \%$ larger than that of the bundle A. Murase's correlation successfully represents this weak dependence of $\alpha$ on $D_{W}$.

Figure 11 shows comparison between the measured void fractions and Murase's correlation (Eq. (12)). Although the void fraction widely ranges from 15 to $90 \%$, Murase's correlation can predict $\alpha$ within about $\pm 10 \%$ for the two bundles.

\section{Conclusion}

Void fractions in the four by four rod bundles under stagnant conditions were measured to examine the applicability of available void correlations. Flow patterns were also observed by using a high-speed video camera to examine the relation between flow patterns and the void fraction. As a result, the following conclusions were obtained:

( 1 ) Dependence of the void fraction $\alpha$ on the volumetric flux $J_{G}$ changed when $J_{G}$ was large enough to cause the formation of large bubbles, which occupy most of the crosssection of the bundle.

( 2 ) Murase's correlation for $\alpha>0.33$ well predicted the void fraction in the two kind of rod bundles having different dimensions under the stagnant condition. 


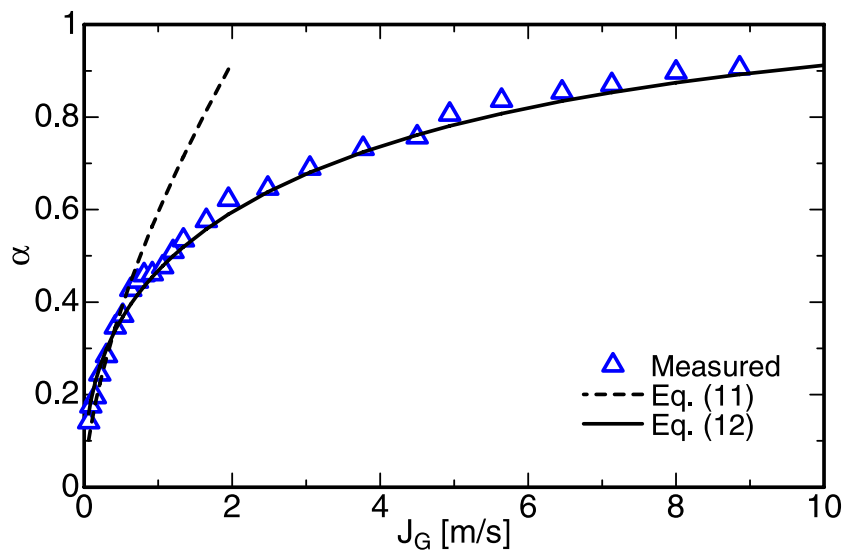

(a) Bundle $\mathrm{A}$

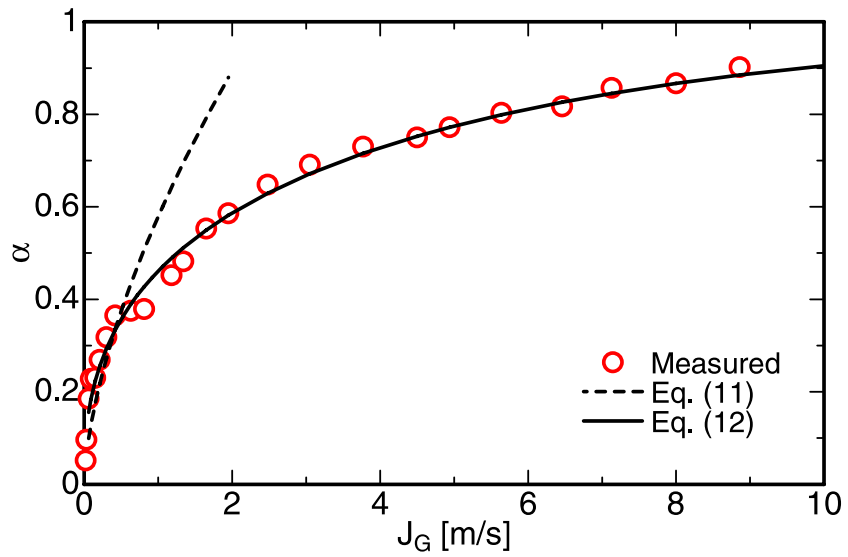

(b) Bundle B

Fig. 10 Void fractions evaluated by using Eqs. (11) and (12)

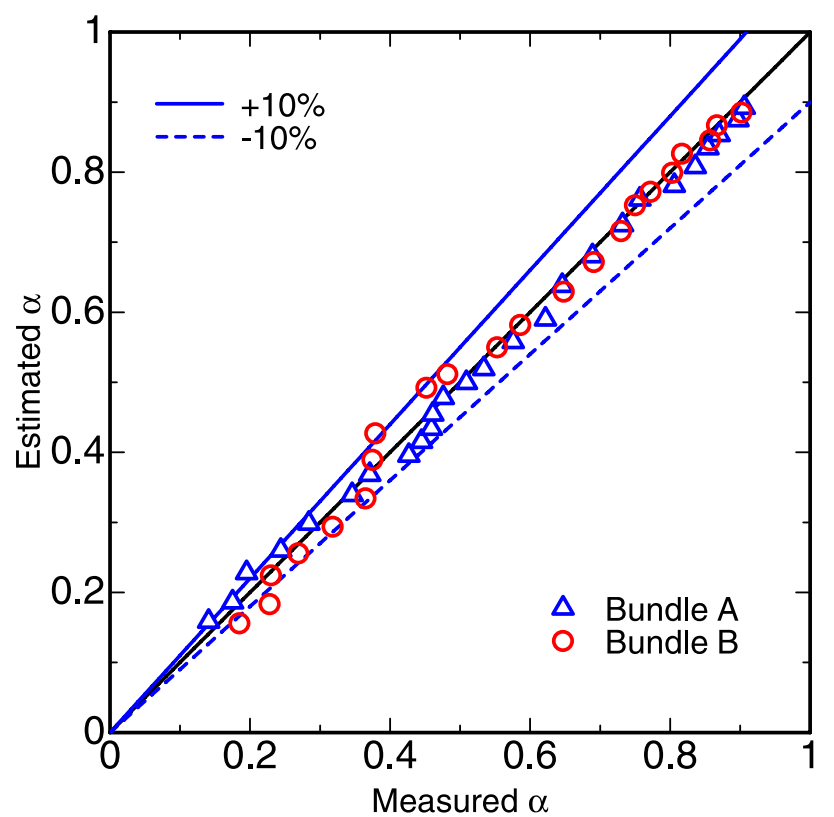

Fig. 11 Comparison between measured data and estimation based on Murase's correlation 
Appendix
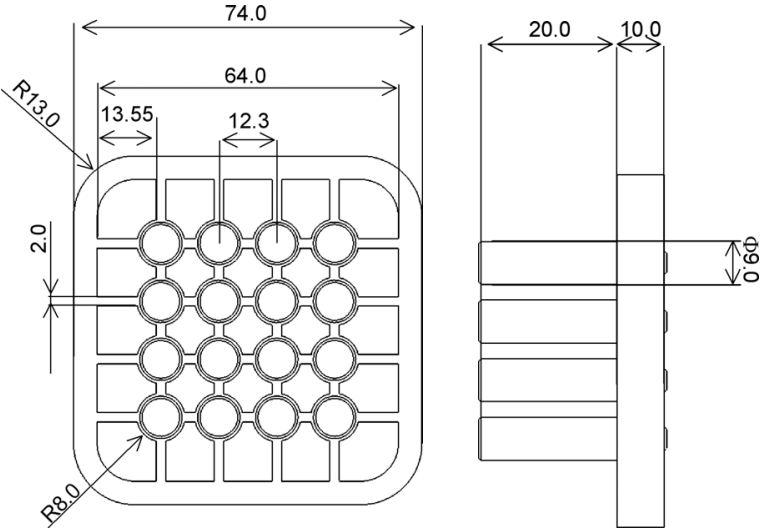

Fig. A Lower tieplate (unit : mm)
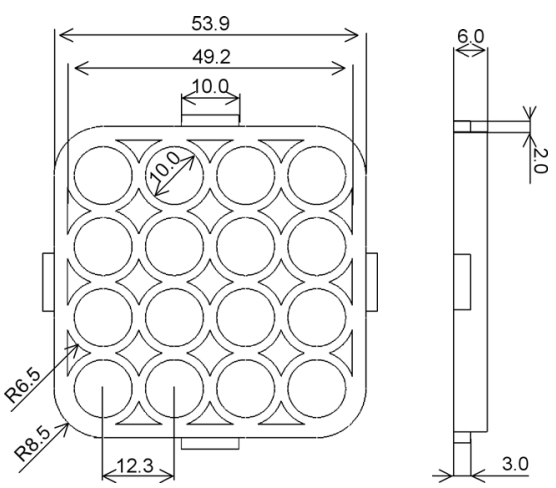

Fig. B Upper tieplate (unit : mm)

\section{References}

( 1 ) Minami, N., et al., Countercurrent Gas-Liquid Flow in a Rectangular Channel Simulating a PWR Hot Leg (1) (Flow Pattern and CCFL Characteristics), Japanese Journal of Multiphase Flow, Vol. 22, No. 4 (2008), pp. 403-412.

( 2 ) Ward, L. W., et al., Consequences of the Loss of the Residual Heat Removal Systems in Pressurized Water Reactors, NUREG/CR-5820, Idaho National Engineering Laboratory, (1992).

( 3 ) Naff, S. A., et al., Thermal-Hydraulics Processes During Reduced Inventory Operation with Loss of Residual Heat Removal, NUREG/CR-5855, Idaho National Engineering Laboratory, (1992).

( 4 ) Inoue, A., et al., Void Fraction Distribution in BWR Fuel Assembly and Evaluation of Subchannel Code, Journal of Nuclear Science and Technology, Vol. 32, No. 7(1995), pp.629-640.

( 5 ) Sadatomi, M. et al., Void fraction and Pressure Drop in Two-Phase Equilibrium Flows in a Vertical $2 \times 3$ Rod Bundle Channel-Assessment of Correlations against the Present Subchannel Data, JSME International, Ser. B, Vol. 49, No. 2(2006), pp. 279-286.

( 6 ) Osakabe, M., Koizumi, Y. and Tasaka, K., Interfacial Drag Coefficient of Air-Water Mixture in Rod Bundle. Journal of Nuclear Science and Technology, Vol. 21, No. 11(1984), pp. 882-884.

( 7 ) Suzuki, H. and Murase, M., Countercurrent Air-Water Flow in Two vertical Channels. Journal of Nuclear Science and Technology, Vol. 23, No. 5(1986), pp. 461-468.

( 8 ) Kataoka, I. and Ishii, M., Drift-Flux Model for Large Diameter Pipe and New Correlation for Pool Void Fraction. International Journal of Heat and Mass Transfer, Vol.30(1987), pp. 1927-1939. 
( 9 ) Murase, M. et al., Countercurrent Gas-Liquid Flow in Boiling Channels. Journal of Nuclear Science and Technology, Vol. 23, No. 6(1986), pp. 487-502.

(10) Mizutani, Y. et al., Two-phase Flow Patterns in Four by Four Rod Bundle. Journal of Nuclear Science and Technology, Vol. 44, No. 1(2007), pp. 894-901.

(11) Zuber, N. and Findlay, J. A., Average Volumetric Concentration in Two-Phase Flow System, ASME, Journal of Heat Transfer, Vol. 87(1965), pp. 453-468.

(12) Ishii, M., One-Dimensional Drift-Flux Model and Constitutive Equations for Relative Motion Between Phase in Various Two-Phase Flow Regimes, ANL 74-77, (1977). 